\title{
Gianfranco Rubino, Lire Didier Daeninckx
}

\section{Fabio Scotto}

\section{(2) OpenEdition}

\section{Journals}

\section{Edizione digitale}

URL: https://journals.openedition.org/studifrancesi/5778

DOI: 10.4000/studifrancesi.5778

ISSN: 2421-5856

\section{Editore}

Rosenberg \& Sellier

\section{Edizione cartacea}

Data di pubblicazione: 1 septembre 2011

Paginazione: 460

ISSN: 0039-2944

\section{Notizia bibliografica digitale}

Fabio Scotto, «Gianfranco Rubino, Lire Didier Daeninckx», Studi Francesi [Online], 164 (LV | II) | 2011, online dal 30 novembre 2015, consultato il 17 novembre 2021. URL: http://journals.openedition.org/ studifrancesi/5778 ; DOI: https://doi.org/10.4000/studifrancesi.5778

\section{Questo documento è stato generato automaticamente il 17 novembre 2021.}

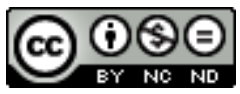

Studi Francesi è distribuita con Licenza Creative Commons Attribuzione - Non commerciale - Non opere derivate 4.0 Internazionale. 


\title{
Gianfranco Rubino, Lire Didier Daeninckx
}

\author{
Fabio Scotto
}

\section{NOTIZIA}

GIANFRANCO RUBINO, Lire Didier Daeninckx, Paris, Armand Colin, 2009 («Lire et comprendre. Écrivains au présent», 4), 191 pp.

1 Autorevole e riconosciuto studioso della narrativa novecentesca e dell'extrême contemporain Gianfranco Rubino dedica uno studio accurato e singolare a un autore fra $\mathrm{i}$ più letti dell'odierno panorama francese e non solo, cercando di mettere in luce l'eclettismo e la poliedricità del suo talento tali da farne ormai ben di più di un autore di polizieschi, oltre che un innovatore all'interno dello stesso genere polar, per la sua capacità di aprirlo alla storia e alla dimensione dell'«anamnèse collective du passé national» (p. 5), come ben spiega nell'Introduction (pp. 5-8). Il caso Daeninckx è infatti quello di un autore che, pur memore della lezione dei maestri di genere, ha saputo anche affrancarsene esplorando altri territori espressivi meno paraletterari quali la novella, il romanzo, il testo teatrale, nonché la sceneggiatura cinematografica o televisiva e i fumetti, con una costante attenzione alla dimensione etica e collettiva delle dinamiche narrative, sempre tributarie, oltre che della finzione immaginativa, anche del portato storico di un'epoca ben connotata e riconoscibile, esplorata attraverso la scrittura e la riflessione. Ne emerge la figura di un libertario ribelle apologeta di taluni modelli rivoluzionari antiautoritari.

2 Strutturato in tre capitoli, lo studio prende in considerazione nel primo (Contexte et enjeux, pp.9-51) il contesto storico-culturale del decennio nel quale Daeninckx esordisce come narratore con Meurtres pour mémoire (1984), ovvero quegli anni Ottanta nei quali, venuto meno l'impulso palingenetico sessantottino, il romanzo cerca di aprirsi nuovamente al mondo esterno. Ne derivano un nuovo impegno e una nuova vitalità attestati da opere coeve di autori come Toussaint, Ernaux, Echenoz, Michon, 
Bergounioux, Germain, Rolin, per non citarne che alcuni, i quali, pur nella varietà delle loro modalità stilistico-formali e tematiche, cercano un nuovo rapporto più veritiero con il mondo urbano e rurale, interrogando tanto lo statuto del racconto quanto la rappresentazione memoriale della realtà circostante e del vissuto soggettivo e collettivo. Da questa riflessione scaturisce anche il néo-polar di autori come Jonquet, Fajardie, Pouy, Vilar, Delteil, rispetto al polar tradizionale teso non tanto alla ricerca di un colpevole da punire quanto piuttosto alla ricostruzione di un'atmosfera sociale più ampia propria del romanziere e del suo universo. Rubino ben tratteggia l'orizzonte storico-temporale collettivo e individuale all'origine dell'opera di Daeninckx, più sensibile ai modelli ottocenteschi che alle produzioni metadiscorsive degli anni Sessanta e Settanta (p. 17). Il secondo capitolo (Territoires et trajets, pp. 52-135) è dedicato all'universo romanzesco, alle tecniche e alle costanti dell'opera, con particolare riferimento alle dinamiche spaziali, da sempre elemento particolarmente presente alla riflessione di Rubino, dalla metafora periferica, circoscritta da «limites à interroger, à traverser, à déplacer» (p. 123) entro le quali è confinata un'emarginazione ingiustamente presa a capro espiatorio di ogni male e in ciò metafora non solo topografica, al modo più generalmente inteso nel quale il potere esercita con cinismo la sua perenne recita di sopraffazione difficile da interrompersi. Il terzo capitolo (Dialogues et résonances, pp.136-172) è rivolto allo studio delle interconnessioni fra $\mathrm{i}$ saperi e i generi, dalla fotografia al cinema, dalla pittura al disegno, nella fecondità spuria di un'ispirazione che non rinuncia a nessuno stimolo del reale per alimentare la propria creatività, al di fuori della legittimità estetica di ogni restrizione di genere, che l'A. auspica anche nella Conclusion (pp. 173-175) superabile dalla ricezione critica odierna. In appendice un interessante testo dello stesso Didier Daeninckx, Du roman et de l'éclosion des fleurs de paulownias, pp. 176-181, degli Éléments biographiques (pp. 182-183) e una Bibliographie (pp. 184-189). 